\title{
The Contribution of Descriptive Assessment to the Student's Emancipation: Theoretical Considerations
}

\author{
Ioannis H. Konstantinou \\ Educator, $\mathrm{PhD}$ \\ University of Ioannina, Greece
}

\begin{abstract}
The purpose of the article is to highlight the contribution of descriptive assessment to the students' emancipation and, in particular, to their self-determination. Introductory, a reflection on the pedagogical purposes of the school is developed, which includes the emancipation of the students. Next, the central concepts of the subject are identified, such as "descriptive evaluation/assessment" and "emancipation". Then, emancipation is approached as a pedagogical pursuit of the school and the theoretical and practical way in which the teacher, utilizing educational as well as valuation processes, contributes to the creation of conditions for the promotion and strengthening of the students' emancipation. Regarding the descriptive evaluation, its role is defined as a technical attribution and recording of the students' performance and an attempt is made to highlight, through the relevant theoretical considerations, its essential contribution to the promotion of the students' emancipation and selfdetermination.
\end{abstract}

Keywords: school purposes, descriptive evaluation/assessment, emancipation, self-determination

\section{Introduction}

It is widely assumed, at least by the experts, that school is an important social institution, the pedagogy and organization of which express educational policy and, at a broader level, a specific situation of social reality. So, the way by which school uses its pedagogic character to face the individual as a student, to which extent it is independent or dependent, the degree by which it promotes its pedagogic and democratic processes and, in general, how seriously school takes its pedagogic role, is mainly a responsibility of the state and, specifically, of the pursued educational policy.

According to its pedagogic and social mission, school, through its functions and, specifically, the educational (edification) and socialization processes, acquaints the student with the normative-cultural elements, which are related to values, rules, practices, orientations and perceptions of the in-school and out-of-school environments aiming at the formation of the student's personality and his integration into the social system. This frame includes all those practices that appear in the school environment either as desirable and necessary or as feasible and justified. The pedagogic interest that this specific function presents to a high degree, is undoubtedly related to the kind of education and socialization that school offers, in order to accomplish these two profound and important aims. So, the way and the means by which school materializes these two functions are of great pedagogic interest, as well as the issue of the guide (gnomon) that school has. Evermore, school, through the process of assessment and evaluation (Gipps, 1992), aims to determine the degree of the student achievement of educational objectives on the one hand and on the other to identify its shortcomings, inadequacies, but also its possibilities, which will obviously lead to the taking of the respective didactic and pedagogical measures, which would contribute to the feedback and upgrading of (the effectiveness of) the educational process (Konstantinou \& Konstantinou, 2017).

This paper is mainly a theoretical-discussion one, which uses, in a synthetic framework, the existing on the subject literature to answer the questions set, which are the following:

- Whether emancipation constitutes a pursuit of the school which is related to its main pedagogical purposes?

- Which is the pedagogic value of descriptive assessment for the educational process and, specifically, for the student?

- How does descriptive assessment contribute to emancipation and, more specifically, to the student's selfidentification during the educational and assessment process?

Methodologically, the paper, firstly, elaborates on the major goals of the school at both, the learning and the socialization levels. It, then, draws on the conceptualization of the idea of student's emancipation as a schooling output and investigates the ways by which this could be supported through descriptive assessment in order to approach the school' main goals.

\section{Basic pedagogic goals of school in the educational and evaluative process}

From clear pedagogic and social aspects, school should satisfy, to a greater degree, the needs and expectations of the individual as well as of the society to the benefit of both. Through education and socialization, school tries to 
help the student to acquire his human and social characteristics and, finally, to form an emancipated and mature personal and social "self"; even more, through completeness in communication and practice, to create an, as complete as possible, personality (Alahiotis \& Karatzia-Stavlioti, 2006; Konstantinou \& Konstantinou, 2017). However, the way in which pedagogical communication is organized and, in particular, the form that education takes in the school environment is a question. The characteristics of the child's social behavior, as well as his personality as a whole, depend to a significant degree on this form. Therefore, in this direction, the orientations and, in general, the way in which the school carries out its pedagogical and social mission and, consequently, the form of implementation that the pedagogical role of the teacher acquires, play a role.

There is no doubt that the teaching process is important for the acquisition and search of knowledge and the development in students of useful skills and abilities, as long as its construct is based on didactic principles and pedagogical orientations. School education contributes to a catalytic degree in the formation of perceptions and attitudes that determine the very coexistence of the members of a society and, consequently, its very function, development, existence and perspective. This role of schooling becomes even clearer if one considers the peculiarities and dysfunctions of today's societies in terms of environmental, technological, cultural, economic, communication and ideological aspects. Through school education, today's citizen must be equipped with those skills, abilities and strategies to be able to effectively manage all the individual and social issues that arise on a daily basis. This means that the school creates such educational conditions that contribute, so that the knowledge provided is related, among other things, to the social reality of the student and is used in this direction, to facilitate him to learn to think, search and processes information, to express views freely and challenge and resist rational arguments. At the same time, it must teach him to limit his behavior and to respect the rules, the culture and his fellow human beings. In other words, the aim of the school should be the prevalence of child-centered educational conditions, which contribute decisively to the emancipation of the student (Karatzia-Stavlioti \& Lambropoulos, 2006; Konstantinou \& Konstantinou, 2017).This emancipation might also be enhanced through the school curricula, as, for example, the cross-thematic programs of study in Greece (Alahiotis \& Karatzia-Stavlioti, 2006). They may also be promoted by international organizations, such as the OECD in the PISA exams (2004).

In relation to the theme of this paper and in a clearly pedagogic frame, it is supported (Loser \&Terhart, 1991: 859860 ,Konstantinou, 2015) that through descriptive assessment the following may be achieved:

- The establishment of a school climate, which leaves room for personal communication and activity between the teacher and the students (school as a community of life).

- The provision of opportunity for release and self-determination to teachers and students within the framework of regulations and rules.

- Providing opportunities for various forms of social life, in addition to the teaching process, which contribute to the formation of the student's identity.

- Providing assistance to students in a school as a place that will give priority to the needs, interests and, more generally, in the lives of children and young people.

Specializing the approach, on a rhetorical-theoretical basis, one would naturally expect the school's requirement for performance, as well as for the evaluation of performance, to take such a form as to contribute to:

- the creation of self-active, conscious and deliberate learning, that is the formation of work and learning ability and, in general, behavior,

- the development of effort readiness and controlling behavior for performance, that is developing readiness and capacity for performance,

- the development of interest, creativity, self-action, initiative, exploratory ability and joy in learning,

- the development of social sensitivity and perception,

- The reinforcement of the student's trust to his own abilities, etc.

(Kalantzis\& Cope, 2008; Nikita, Karatzia-Stavlioti\&Alahiotis, 2015; Konstantinou\&Konstantinou, 2017; Lichtenstein-Rother\&Röbe, 1982: 82).

In any case, the teacher has decisive pedagogical and institutional-organizational power in all these educational processes and, in general, in all the functions of the school. He is the main person in charge and the protagonist of the school processes. He is responsible for the organization of educational processes and in particular education. $\mathrm{He}$ comes first and foremost in direct and constant communication with the student. The quality of pedagogical communication and relationship with the student depends on him, for example the way he treats the student as a personality and, in general, the form in which he deals with the practical issues of school life. By what practice, that is, does he express his social values, rules, orientations, perceptions, etc.

In other words, what circumstances does he shape with his behavior for dialogue, free expression of views, rational argumentation, acceptance of the cultural and religious heterodoxy and diversity of the other, pluralism of ideas, criticism and self-criticism, understanding, kindness, equality, cooperation, friendliness and generally respect for 
the other person's personality? What are the teacher's goals in organizing pedagogical processes? Is it, for example, the enhancement of the student's self-perception or the formation of manipulative, submissive, stigmatized, insecure, frightened, heteronomous and egocentric individuals? Does it encourage or discourage the student more? Does he show understanding for his problems or is he indifferent? The student participates in school processes, so as to form an increased awareness of his responsibilities and so on? (Konstantinou \& Konstantinou, 2017; Lawton, Cains \& Gardner, 2004; Sawyer, 2006).

Therefore, from this approach it is clear that the type of school education and socialization of the student and in particular the formation of his personality depends to a large extent on the teacher. This means that it should not escape the teacher's attention that every action is pedagogically and socially significant and, therefore, each time sends the corresponding message to the student. In other words, any behavior of the teacher certainly has a positive or negative effect on the formation of the student's personality. The teacher's awareness of these data, issues and assumptions will help the teacher to manage his role, as well as his relationship with the student, more realistically, humanely and mainly pedagogically(Alahiotis \& Karatzia-Stavlioti, 2006; Kalantzis \& Cope, 2008; Lawton et al, 2006).

\section{The emancipation and self-determination of the student as a pedagogical pursuit of the school}

By analyzing the procedures, with which the teacher is in charge, one can identify the pedagogical dimensions in his role, even at a theoretical level. Therefore, based on the pedagogical nature of these procedures and, in general, on the claims and expectations related to the specific pedagogical role, and as these arise from the point of view of the pedagogics, the teacher should be oriented: to expectations, needs, interests, problems and individual characteristics of each student.

At the same time, the teacher must transmit those cultural elements, such as knowledge, skills, rules, attitudes, values, messages, etc., required by the various social sectors and society at large, through specially designed pedagogical and didactic organizational processes. and communication. This means that the teacher has those professional qualifications that allow him to meet these expectations and requirements, contributing, in this sense, both to the comprehensive development of the student's personality and to the feeding the various social sectors with capable and qualified people. This does not mean that the child should only acquire knowledge in specific subjects, for example history, mathematics, etc., but much more, the school aims to give pedagogical meaning to all school processes, so that to contribute to the most complete development of the child's personality. To contribute, that is, in such a way that the child becomes mature, autonomous, responsible, consistent, emancipated, free, democratic, with creative and critical thinking, with respect for the identity of others, etc.(Alahiotis \& Karatzia-Stavlioti, 2006; König 1991;Konstantinou, 2015; Lawton, 2004; Sawyer, 2006).

However, it turns out by relevant research (Kalantzis \& Cope, 2008) that the forms in which the education practiced by the teacher occurs and, in particular, the school education, depend on macro-level and micro-level factors. Such factors, in terms of macro-level, the historical, political, economic, religious, scientific, technological and more broadly sociocultural (social reality).Therefore, its purposes are related to the specific social structure and, in general, the way of organization and operation of the whole social system. From a micro-level point of view, we mean the school reality with all the parameters that enter it and the environment that shapes it (Konstantinou, 2015; Konstantinou \& Konstantinou, 2017; Lawton, 2004; OECD, 2004).

Based on child-centered or democratic education, which is a combination of positive emotional behavior and rational autonomy, education aims, through processes of dialogue, friendship, cooperation, encouragement, understanding, acceptance, self-action, free expression of participation and active student action of school pedagogical interaction, to lead student to his emancipation, to his independence, to his self-discipline, to his selfdetermination and finally to his self-sufficiency. In this education, the student is treated as a personality with his biological, emotional, mental, cognitive and socio-cultural peculiarities.

For this reason, he is strengthened and praised for his success and encouraged in his failed endeavor.Through processes of co-organization, synthesis of rules and cooperation, this education aims to form a student personality liberated, emancipated, responsible, consistent, democratic and free, without religious and cultural intolerances, as well as with social and human ones (Konstantinou \& Konstantinou, 2017; Pyrgiotakis, 1989).

Nevertheless, in relevant research (Weinert, 1977: 382, Ulich, 1981: 173, Flitner, 1997: 21-111, as discussed in Konstantinou, 2015) it has been shown that child-centered-democratic education, as well as other types of education, have decisive effects on the individual's personality. Specifically, the practice of child-centered education helps to develop the individual strong self-perception, emotional stability, ability to resist, critical ability, positive mood for cooperation and self-action.

In general, he may develop into a person who works emancipated, takes initiatives and feels satisfied and safe, because, among other things, they show him confidence, give him opportunities to co-decide and generally respect 
him as a personality. He is a liberated, creative and active person with high aspirations and who appropriates with responsibility and ease the various roles, which, of course, does not accept them relentlessly and passively.

In summary, one finds that such effects of education contribute to the promotion of student emancipation, which is considered one of the most important pedagogical aspirations of the school, at least at a theoretical level and, ultimately, its self-determination. The concept of "emancipation" is understood here as the result of liberation and independence of the individual from any power and influence, related to basic parameters of personality development, including self-determination. As the skill of self-sufficient and spontaneous social presence and activity, inside and outside school reality, especially in today's changing and demanding society. That is, as the concept opposite to that of manipulation, which is characterized by dependence, commitment, coercion, submission and guardianship (Civita, 2020; Dermitzaki, 2017;Grlolios \& Gounari, 2016; Konstantinou, 2015).

We understand the concept of "self-determination" as a decisive contribution of emancipation to the individual and, at the same time, as an important aspect of his personality, according to which the individual himself is able to regulate and shape his views, attitudes, actions, goals, choices and, overall, his behavior. That is, it is a selfrealization, a self-regulating tendency, action and behavior (Konstantinou, 2015, Konstentinou \& Konstantinou, 2017; Wehmeyer, 2005). And, according to the latest approaches to learning theories, one way to promote independent learning, achievement of personal goals and equal educational opportunities for all students, is to create a learning and pedagogical environment where students will be educated and learn how to function independently and creatively(Nikita et al, 2015; Sawyer, 2006). The above is more important in the societies of the today's postmodern world that are characterized as ontologically "moving" societies (changing, transforming) (Civita, 2020). In such a society education should be enabling the students to cultivate learning and attitude skills through an autonomous, independent and self-regulated learning and social process (Dermitzaki, 2017, Konstantinou, 2015; Lawton et al, 2004).

It is considered crucial to promote the student's perceptions, knowledge, attitudes and skills, which contribute to effective learning and socialization both in school and in society at large, such as positive self-perception, clarification of personal learning goals, learning skills, the skills of managing individual and social issues, the skills of critical thinking, the independence of thought, the initiatives etc. Skills and qualities, that is, that lead to the liberation and, ultimately, to the emancipation of the student. An important factor in a student's emancipation is his clear self-image and self-awareness of his abilities. An additional condition for achieving self-determination, which also contributes to efficient learning, is that students are able to adequately recognize and control not only their motivations but also their emotions, so that they do not constitute an obstacle to their activity and achievement of their goals. Thus, students become more aware of their potential and performance, experiencing a more positive sense of personal effectiveness and personal control (Dermitzaki, 2017, Konstantinou, 2015; Sawyer, 2006).

\section{The relation between descriptive assessment and student emancipation}

In school, each student is evaluated according to his performance in specific cognitive subjects with special emphasis on mathematics and language. On the contrary, the existing school almost systematically ignores its pedagogical and didactic orientations and, in particular, the student's performance and progress in vital areas, such as social action and communication activity, ie. cooperation, responsibility, organization, its initiative, its creation, its consistency, its sensitivity to the environment, issues which are considered primary goals for societies by international organizations, such as the United Nations(UN) and so on (Hentig, 1976; UN, 2015;Xohellis, 2010). That is, there appears to be an inconsistency between the officially proclaimed socializing-pedagogical mission of the school (theoretical dimension) and the practice it adopts (practical dimension). This is why, based on their analysis and research, many scientists have called this school a "school of performance."(Gipps, 1992; KaratziaStavlioti \& Lambropoulos, 2006).

In particular, the school, with the weight it attaches to its selective function, makes its pedagogical character precarious and, from an area in which education and learning must be provided, it becomes a "playing field" for the acquisition of points and privileges. This means for most students that they have to constantly prove that they are "better" than their classmates. (Lichtenstein, Rother, Heckhausen \& Hentig, 1976; Xohellis, 2010).

However, the pedagogical function of assessment is not aimed at hierarchical judgment and grading of the student, but at the assessment of the educational process and the achievement of its objectives as well as the identification of potential learning difficulties, with the central goal of timely and appropriate pedagogical measures in this direction. This stage is the ultimate, the final but also of the most decisive role, from a pedagogical point of view, as in the case of the evaluation and assessment of both the learning process and the student's performance. In this sense, the evaluation of school performance aims on the one hand to control the formed learning objectives and to diagnose the learning process and on the other hand to diagnose the abilities and skills of the students. 
This diagnosis, which serves both the teacher and the student, contains information about possible deficiencies of the student in certain cognitive areas, about the student's ability to attend the teaching of a topic or a unit or a course and about the success or failure of certain changes in teaching methods. The pedagogical function of assessment, interpreted in this way, is based on the assumption that the assessment of student performance and its communication is able to mobilize the individual to improve the level of learning and, in general and plays a positive role in the development of his personality. And, of course, such an orientation must contribute to increasing the student's interest in performance (Broadfoot \& Black, 2004; Konstantinou \& Konstantinou, 2017).

The technique of rendering and recording the student's performance, which is considered to move in this direction and is closer to the pedagogical content of the assessment, is descriptive assessment. And this is because it allows the student's performance to be described differently, individually and with more clarity and completeness. In such a way, so that students and parents understand not only the weaknesses, shortcomings and strengths of the student in the teaching and learning processes, but also important aspects of the school work, participation and activity of the student, such as, for example, his learning, work and social behavior and not only the results, which constitute the individual peculiarities of his personality. Another positive point is that with the descriptive evaluation, it is possible to describe even the learning processes, as well as their outcome and development (Bartnitzky-Cristiani, 1987; Gipps, 1991; Konstantinou, 2007; Nikita et al, 2015).

In other words, in this form of performance and capture of the result of the assessment, at the center of the process is the individual learning process of the student, from which on the one hand his interests, needs and personal peculiarities are highlighted and on the other hand all the factors involved are weighed in the organization and practical application of learning processes. The teacher, taking into account the individual and social characteristics of students, describes their learning, emotional, cognitive, mental and, in general, their social behavior and development, without being forced to resort to standardized measurements of performance. In this sense, an effort is made to pinpoint the performance, the development, the particularities and, in general, the progress of each student individually; in this way limiting the processes that lead to comparisons with the reference group, ie classmates, without ignoring the social context in which the group (class) to which the student belongs and operates (Konstantinou \& Konstantinou, 2017).Thus, the teacher, through this diagnostic form of assessment and, in general, from the assessment to its pedagogical form, tries on the one hand to upgrade the communication and learning conditions and on the other hand to identify the learning and other peculiarities of each student, with the ultimate goal of removal or mitigation of the presented difficulties or shortcomings and the upgrading and improvement of the individual, as well as its overall capabilities. This stage is the ultimate purpose of pedagogical assessment, consisting of a set of information that attributes or describes the distance between the student's level of learning in the particular situation and the level of learning where it is sought to reach or, otherwise, is the information provided to students for the quality of their performance and which are intended to modify their thinking or behavior in order to improve learning(Sawyer, 2006). The teacher, that is, through a systematic organization and a continuous evaluation of learning processes, systematically observes step by step the development of the student on a cognitive, emotional and mental level. As it is understood, this stage concerns all the functions of the school and, more specifically, the processes of teaching, education, socialization (in today's societies) and evaluation (Civita, 2020; Konstantinou \& Konstantinou, 2017, Rekalidou, 2011).

The information that the teacher collects and attributes to the student, in the context of descriptive assessment, makes him aware and responsible for his actions. This kind of evaluation leads, in fact, to processes of personal judgment, evaluation (eg causal performance returns) and reactions to the result of his performance (eg personal satisfaction).

Self-regulating and, therefore, emancipated students evaluate the result of their effort, evaluate whether the initial learning goal has been achieved, consider the possibilities and limitations of themselves in the specific learning condition, think about how they can cope more effectively in a future similar learning situation. and adapt, if necessary, mental and cognitive practices to new conditions or create new ones, to be available for the future. Thus, it leads to relevant questions such as "How well am I doing so far in relation to my goal?", "Do I need to change something?", "Am I as focused as I need to be?", "How will I maintain and increase my interest in this boring but necessary lesson? "," What am I doing well so far and what not? "," How will I proceed with the required changes?", "Is the material and other things I work with appropriate?", "Have I achieved my goal? To what extent? "," How can I improve in the future? ". All these evaluation processes contribute de facto to the development of strategies, such as skills, which favor the student to control and regulate his performance, in order to be led more effectively in achieving his goals (Alahiotis \& Karatzia-Stavlioti, 2006; Dermitzaki, 2017: 37;Efklides, 2008; Konstantinou \& Konstantinou, 2017). It could be argued that, nowadays, there is a move to rethink more radically the practices and priorities of assessment if it is to respond to human needs rather than to frustrate them (Broadfoot \& Black, 2004). 
Therefore, the contribution of descriptive assessment to the student's emancipation comes to mean the opportunity it offers the student to free himself from authoritarian and aggravating influences, which characterize both school reality (eg educational and evaluation processes) and social reality (eg family environment), and which prevent or even rivet the student from being able to function based on his own interests, his own needs, his own inclinations and his own aspirations. That is, liberation from authoritarian influences, such as the memorization and reproduction of ready-made knowledge, the pressure and oppression for high performance, the pursuit of grades as an end in itself (grading), the unbridled competition between students, and so on.

\section{Final findings and remarks}

Summarizing the above analysis, it should be pointed out that the parameters emerging from the pedagogical use of descriptive assessment and which contribute to the emancipation of the student and, at the same time, compose it, are the following: critical thinking, self-criticism, self-knowledge, self-determination, knowledge, applause, reward, self-perception, self-esteem, autonomy, initiative, etc. Parameters that presuppose or require systematic monitoring and recording of student performance, pedagogical organization of communication-relationship between teacher and student, information of all involved, listening, dialogue and, overall, well-organized school climate.

In other words, and as highlighted by the present approach, descriptive assessment leads to the revelation of all aspects of the student's personality, abilities, inclinations, skills, knowledge and shortcomings. It leads the student to know himself and all aspects of his personality, it leads to self-evaluation, critical thinking, self-knowledge, selfconfidence and, finally, his emancipation. However, how practical is all this in a, for example, Greek school, where, even after the related with the aforementioned qualities application of the cross-curricular approach in compulsory education and the supposed predominance of basic competences, they still dominate: the inflation of the cognitive material, the reproduction of ready knowledge, the one-dimensional teaching process, the entrance exams (preparation even from the primary school), the degradation of the education, the exams processes that require memorization rather than the development and use of critical thinking, the recording of performance with techniques that do not contribute to the fuller information and information of the student, to know his potential and to make efforts to overcome obstacles?

Therefore, the information that results from the descriptive evaluation and which is the product of systematic observations of the teacher must applaud the student's efforts, strengthening, in this sense, his self-perception and confidence in his abilities and, in general, in himself; properties that can release his dynamics and lead to his emancipation. Thus, an emancipated student is given the opportunity to proceed with the assessment of the requirements of the learning work in time and effort. At the same time, the student can plan his course of action, select the appropriate strategies for this purpose and organize and manage more efficiently the parameters that lead to the achievement of his goals (Dermitzaki, 2017, Konstantinou \& Konstantinou 2017; Sawyers, 2006).

As it has already been pointed out, the evaluation from a pedagogical point of view is necessary not to be used as a disciplinary or punishment measure, which can stigmatize the student as a failure, marginalize him and, overall, have a negative effect on his personality. The student is at school to be educated, to be socialized and, in particular, to help shape his cognitive, emotional and mental level and, in general, his personality. Therefore, the school must create favorable conditions for learning, education, socialization and assessment.

\section{References}

Alahiotis, Stamatis, N. \&Karatzia-Stavlioti. E. (2006). Effective curriculum policy and cross -curricularity: analysis of the new curriculum design of the Hellenic Pedagogical Institute”.Pedagogy, Culture \& Society,14(2): 119-147.https://doi.org/10.1080/14681360600738277.

Bartnitzky, H. \& Cristiani R. (1987). Zeugnisschreiben in der Grundschule. Heinsberg.

Broadfoot,P\& Black, P. (2004). Redefining assessment? The first ten years of assessment in education", Assessment in Education: Principles, Policy \& Practice, 11(1): 7-26,

DOI: $10.1080 / 0969594042000208976$.

Civita, A. (2020). "Moving" Society. International Journal of Humanities and Social Science,10 (4): 29-35. doi:10.30845/ijhss.v10n4p5 29.

Dermitzaki, E. (2017). Promoting students' skills: Development of self-regulated learning. Athens: Gutenberg.

Efklides, A. (2008). Metacognition: Defining its facets and levels of functioning in relation to self-and coregulation. European Psychologist, 13: 277-287.

Flitner, A. (1997). Authoritarian or Liberal Education? (translation into Greek: Christias I.). Athens: TIPOTHITOGIORGOS DARDANOS.

Gipps, C. (1992). What we know about effective Primary teaching. London:Tufnell Press.

Grollios, G. \&Gounari, P. (2016). Liberating and critical Pedagogy in Greece: Historical routes and Perspective. Athens: Gutenberg.

Hentig, v. H. (1976). Kritik am Leistungsprinzip der Schule, Schulleistung und Leistungsschule: 43 - 53. Bad Heilbrunn/OBB. 
Kalantzis, M., \& Cope. B.(2008). New Learning: Elements of a Science of Education. Cambridge: Cambridge University Press.

Karatzia-Stavlioti, E. \&Lampropoulos,H. (2006). Evaluation, effectiveness and quality in education. Educational Planing and Economy. Athens: Gutenberg. (in Greek).

König, E. (1991). Werte und Normen in der Erziehung». Roth, L. (Hrsg.): Pädagogik: Handbuch für Studium und Praxis: 799-812. München: Ehrerwirth.

Konstantinou, Ch. (2007). Assessing student performance as pedagogical logic and school practice. Athens: Gutenberg.(in Greek).

Konstantinou, Ch. (2015). The good school, the competent teacher and the appropriate education as a pedagogical theory and practice. Athens: Gutenberg.(in Greek).

Konstantinou, Ch. \&Konstantinou, I. (2017). Evaluation in education: The evaluation of the educational work, the teacher and the student as theory and practice. Athens: Gutenberg. (in Greek).

Lawton, D., Cairns, Jo.\&Gardner, R. (2004). Education for Citizenship.London: Bloosmbury Publishing.

Lichtenstein-Rother, I. \& Heckhausen, H. \& Hentig, v. H. (1976). Schulleistung und Leistungsschule. Bad Heilbrunn/OBB.

Lichtenstein-Rother, I \&Röbe, E. (1982). Grundschule. Der pädagogische Raum für Grundlegung der Bildung. München.

Loser, F. \& Terhart, E. (1991). «Schule als Lebensraum - Schüler und Lehrer».

Nikita, V., Karatzia-Stavlioti, E., \&S.N.Alahiotis, S.N. (2015). Evaluating the Pedagogical Effectiveness of the New Learning Theory of "Biopedagogism". International Journal of Assessment and Evaluation, 22(4): 45-60.

OECD, (2004). Problem Solving for Tomorrow's word. First Measures of Cross - Curricular Competences from PISA 2003. Washington DC, OECD.

Pirgiotakis, I. (1989). Socialization and educational inequalities. Athens: Grigoris. (in Greek).

Rekalidou, G. (2011). Assessment of learning or assessment for learning? Athens: Pedio.(in Greek).

Sawyer, R.K.(2006). Explaining creativity: the science of human innovation, Oxford/ New Y.

U.N. (2015). 17 Global Goals for sustainable development by 2030.Available: https://www.sightsavers.org/policyand-advocacy/global-goals/?gclid (20-8-20).

Ulich, D. (1981). Die Lehrer-Schüler-Interaktion. Twellmann, W. (Hrsg.), Handbuch Schule und Unterricht, Band 1: 161-177. Düsseldorf: Schwann.

Xochellis, P. (2010). School pedagogy. Thessaloniki: AdelfiKyriakidi. (in Greek).

Wehmeyer, M. L. (2005). Self-determination and individuals with severe disabilities: re-examining meanings and misinterpretations. Research \& Practice forPersonswithSevereDisabilities, 30(3): 113-120.

Weinert, F. (1977). Die Familie als Sozialisationsbedingung. Funkkolleg: Pädagogische Psychologie», Band 1. Frankfurt am Main: Fischer. 